\title{
DOI: 10.7596/taksad.v5i4.619
}

\section{Tehran Water Museum with the Performance-Oriented Approach to Bionic Architecture}

\author{
Faeghe Farokhizad ${ }^{1}$ \\ Jaleh Sabernejad ${ }^{2}$
}

\begin{abstract}
Form and function of architecture in nature, is a process that is perceived as instinctive as the development of internal growth and creation. The most basic level of commitment to life that reveals itself in the form of materials. Architecture form and shape to the beat and rhythm of the invisible life, in fact, it is a process which gives the project structure and the structure of the plan. Every living organism is driven by unchangeable force. Trying to become more efficient form and function. In the natural area is very important that "performance" is defined as the process and relationship and "form" is defined as a result of this process. Forms of interaction with nature that takes shape and naturally goes in the direction of performance to match its relationship with the wider environment and in the surrounding territory. Methods and new ideas can be learned from nature. Generally architecture is defined as to imagine, design, understanding and build according to circumstances. These problems may in itself was fully functional and to varying degrees, reflecting the economic, political and social project. In any case, it seems that the status quo is not simply satisfying. For this reason, we seek a new agreement that they "answer the question" is called. Therefore, in this study, based on architectural features permit, trying to establish a performance-oriented architecture, nature-based design and natural patterns to be defined by Vitruvius.
\end{abstract}

Keywords: Museum, Water, Bionic, Functionalism, Nature.

\footnotetext{
${ }^{1}$ M.A Architecture Student, Department of Art and Architecture, South Tehran Branch, Islamic Azad University, Tehran, Iran.

${ }^{2} \mathrm{Ph}$. D. Architecture, Assistant Professor, Department of Arts and Architecture, South Tehran Branch, Islamic Azad University, Tehran, Iran.
} 


\section{Introduction}

In recent years, inspiration and metaphor of nature has entered the field of architecture to pave the concern to achieve a complete architecture. Skill in attracting and employing characteristics of human nature and the transition to the knowledge cause the emergence of a trend that there have its roots in the past and is expressed in the form of bionic architecture. The purpose of the proposed bionic architecture discussion, sensitive to the environment and finding a meaning look Locator phenomena. Architects and building designers believe that nature-inspired designs can have a positive effect in reducing environmental damage. For the development of architectural forms found in nature, there are basic rules that can be in the most exquisite buildings and modern architecture applied. Hydrology is the science of understanding the nature of nature, in this study for bionic architecture seems more appropriate. Architectural principles of Vitruvius, an ancient Greek architect is based on three performance architecture, beauty, and strength. The aim of this study is how these three characteristics in the arena reaches bionic architecture. What will be in this project, hydrology is the science of samples. Scientific has a close relationship with a lot of different fields. According to the various forces involved in the overall process architecture, organize and combine. With that in mind in designing and implementing architectural feature, it is necessary that force should be used in architecture to integrate the two parts of nature, water and architecture achieved the pinnacle of design and performance-oriented applications. Beyond pure structures in nature, there is order and perfection. Skill in attracting and utilizing these features and its transfer into human learning marking the emergence of a trend that its roots can be traced from the past. The outcome of this training is expressed in terms of "Bionic". In recent years, inspiration and metaphor from nature into the field of architecture has come to a complete architecture to pave concern. What is today called "bionic architecture" called that the result is that a new approach to architecture and architects working in the most natural structures are trying to resolve failures and human errors in the construction (Margolius, 2009, 89). Architectural form and function in nature is a process that instinctively as the development of growth and the creation of internal and understood. The most basic level of commitment to life that reveals itself in the form of aggregates. Architecture form and shape to the beat and rhythm of the invisible life. In fact, a process which gives the project structure and the structure of the plan. Every living organism is driven by a force unchangeable. Trying to become more efficient form and function. The natural area is very important that "performance" as the relationship and "form" is defined as a result of 
this process. Forms of interaction with nature that takes shape and naturally goes in the direction of performance to match its relationship with the wider environment and in the surrounding territory. Methods and new ideas can be learned from nature (Hagan, 2001, 22). Given that nature is nature's hydrologic science, the study of bionic architecture for the design seems more appropriate. Today, the attention of men towards questions beyond everyday life for out of it are the issues of life unchangeable part of their car and dragged them into the world a new look but yet familiar, that form the alphabet of the nature and context of the universe. The root of all the forms found in nature and architecture has been inspired by natural forms and structures and nature. Recently, this trend more internal logic and morphology natural processes has seen its appearance, in addition to the simulated space environments due to its architecture reflected as part of nature (Golabchi, 2007, 34-35). Architectural principles of Vitruvius, an ancient Greek architect is based on three performance architecture, beauty and strength. In every period of history, architecture analysis, analysis and theories presented. The aim of this study is how these three characteristics in the arena reaches Bionic architecture. The principles of a model for the project is definitely hydrologic science. Science which has a close relationship with a lot of different fields. With the features and patterns in the field and the nature of juice and water elements was to achieve perfection in style, according to (ancient Greek tradition) of the norm or the nature of the matter (as defined by Vitruvius) will be obtained. As Greg Lynn says fitness, beauty and performance in the classical sense is a great value (Vitruvius, 2009, 10-20). Architecture with nature can be divided into two sub-categories. An attitude refers to a type of architecture that the plans of least damage on the environment and on the other hand is trying to integrate architecture with nature. The architectural nature of the sub does not count, but also to the nature and architecture are not separable. The roots of this attitude can be traced modern and organic architecture. Despite the failure of the modern movement in the sense of connection to nature, some of the leaders in the movement, such as Alvar Aalto and Frank Lloyd Wright have tried to emphasize in this regard. Wright buildings blend perfectly with the environment and as part of it. He put the building as a living organism and its environment that every house should form a unit. The burn technology is a means to achieve superior architecture, which in his opinion was the same organic architecture (Golabchi, 2007, 56). According to the relevant processing architecture that various forces as a whole unit, organize and combine and with that in mind in designing and implementing architectural feature, it is necessary that force should be used in architecture to combine two instantiates some water and the height of functional design and performance-oriented architecture achieved. This study emphasizes the 
architectural principles of Vitruvius architecture based on three performance, beauty and strength. One of the basic principles of nature pattern, legality and transformation. Designs inspired by nature, can help to reduce environmental damage caused to the buildings. Bionic architecture in this project, the design of Tehran Water Museum are found in nature in the application of biological systems and engineering systems and modern technology (Margolius, 2009, 89).

\section{Theory and Literature}

Three famous principles of Vitruvius, fermatas, utilities, beauty, respectively, construction, function and form according to Vitruvius's ten-volume book. Beyond the basics, there are apparently normal contractual principles and the principles of Vitruvius natural, logical categories mentioned in the ancient Greek philosophers drew the attention of all is that later. These issues are so universal that not only architecture but also aesthetics and ethics can explain. According to the great Greek philosopher Hippocrates, many things can be learned from imitating animals, such as spiders weaving clothes to look and the swallows building and the singing lark also be engulfed. In relation to how people interact with nature, researchers have offered different divisions, each of which is in place as a valuable source. In relation to how people interact with nature, researchers have offered different divisions which in itself is a valuable resource. Architects have long been inspired by nature. Ever since the conscious human nature is viewed as a case study has tried to identify the geometry in nature. The laws of symmetry in ancient Greece has been carefully studied. It should be mentioned that humans did not invent geometry, but it has discovered. It is believed that in order to achieve a good fit and a nice atmosphere and architecture can be used geometry in nature. Measuring the proportions of the human body and apply it to the design of the space would be space better compatibility and performance. Different terms and words used to refer to the concept of architectural practice; generally four general interpretation of the concept of performance has been achieved: "Transactional interpretation", "biological interpretation", "mechanical interpretation" and "interpretation system". The four words, it is known architectural performance of various aspects of gains and notes on various aspects of what architecture. Architectural form and function in nature is a process that instinctively as the development of growth and the creation of internal and understood. The most basic level of commitment to life that reveals itself in the form of materials. Every living organism is driven by a force unchangeable. Watching the clear water, luster eyes. Water listening to a song and 
music, inspiring people sick and tired of life on the water entrust guardian of physical health and vitality of spirit. The sound of water, drinking water and the breeze are refreshing water and the Spirit. Water the wonders of creation and existence of four main elements where He says: "We've put the lives of everything from water and without water there is no living creature cannot be moved nothing." In conjunction with Bionic architecture and its history, but there is a lot of water in relation to architecture and museum management permit has not been done. Review articles and books transplantation Bionic architecture and its relationship to the Water Museum in architecture to this research. The first chapter examines the aesthetics through history and connection with the triple Vitruvius and later from the perspective of functionalism in architecture will be discussed. The overall research is about bionic and the approaches taken by the science. In every period of history with the introduction of each of the styles and current thinking in architecture, to provide a new definition of the fundamental principles of the architecture of form and function is attempted. These definitions in a wide range of operational needs and perceptions varied aesthetic and architectural space created by the transformation process have been revolutionized.

\section{Background Knowledge of Hydrology}

At the time of the Achaemenid Persian Empire and perfection magnificent leap at the time of the Sassanids, and long-standing knowledge of hydrologic Iranian civilization was highly indebted. Natural human into the water, the geographic region of the Iranian plateau and rare precious liquid, Iranians value the material hundredfold and put it in a special place is extravagance. Anahita, goddess of the waters, the turntable him in the sky clouds and rain and hail, and dew four horses pulled, a large pre-Zoroastrian gods, and worship him in Kangavar (Kermanshah) and Bishabor Gulf is visible, in Avesta has been praised by many and both times Mithras and Ormazd (Ahura Mazda) is placed. Zoroastrianism clean water and a symbol of purity and should continue to remain clean (Amin Zadeh, 2003, 10). Petroglyphs and remnants of ancient Iranian tablets, indicated that the Iranian people have a long and deep groundwater by digging canals meet to split the villages and towns. Several American scientists such as F. Dix in writing a scientific book to organize the water, M. A. Butler in the irrigated by aqueducts in Iran, C.F.Tolman in the book of groundwater, Zhi. B. Korsi in the subterranean, Zhi. Bizhlibin Kat in the hydrology book and Henry Goblot in books of irrigation in California and aqueducts, technically to achieve their water all believe that Los Angeles and Pasadena, California aqueducts, aqueducts, as well as Chile and Mexico, at the 
time of the Spanish domination, engineers, specialists and workers in Iran are made. All ancient civilizations along big rivers like the Nile, Tigris, Euphrates, Indus, Ganges, Huang Ho, Yangtze and etc. were formed and remained in the river. But only civilization that was formed without any huge river and Malekorreqab ancient world was Iran. A significant leap Empire, was due to aqueduct. Iran after the Islamic scholars, Hydrology have studied the various aspects of knowledge. Then, as today includes the study of water flow or water cycle (water cycle) in nature, the flow of water on the ground, groundwater, springs, lakes, seas and oceans and how their waters has been qualitative and quantitative changes (Lahmian, 2003, 33). Great Iranian scientist, in The Remaining Signs of Past Centuries, about high and low river water, springs and curries, Abu Ali Sina in Alaei encyclopedia (Physics) about the sea and tidal influence of the moon on it, Iranian scientists fifth century AD, Abu Hatim Asfazari Ismail Khorasani, atmospheric and meteorological phenomena in the world for the first time in his book, Alavi works, has compiled (called the Father of climate science). The great mathematician and engineer the fifth century AD, Mohammad Ben Hussein Georgian, very interesting viewpoints are Hydrology and water extraction secretly in his book examines the methods and rules to identify groundwater deals. Iranian historian Masudi in Altanbih and Alashraf book, noted the source of rivers and seas, and many water phenomena Iran, is spoken (Raeis Zadeh, 2004, 40-44). Water has long been the most important factor in the world's infrastructure. Due to the specific situation of water resources and uneven distribution of rainfall, frequent droughts, does not conform to the principles of conservation and protection of water resources, throughout the history of human creative mind is preoccupied, so in many ways sought to explore innovative and creative solutions to fix this problem and to think about efficient use of groundwater exploitation techniques and promote further training in this field. Groundwater extraction for white, as one of the surprising phenomena created by humans, according to many historians and researchers also have attracted that this natural and eco-friendly and sustainable systems, today considered the world's advanced countries, and even one of the fascinating subjects are science and education at universities and research centers. Subterranean, hidden inside a lasting legacy and is one of the Iranian scientific and cultural treasures. In fact, subterranean birthplace of the most important monuments of Iran and the outcome of Iranian art and culture, have been developed over generations. Aqueduct from the perspective of the tourism industry and addressing the issue of education and also holding workshops in this field, in addition to revealing the ambiguous corners of indigenous technology in this land, it can count as an excuse to promote scientific development, cultural and economic in Iran. 


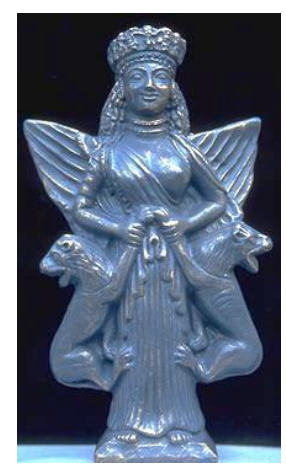

Figure 1. Anahita Izad Banou water source :( www.kianavahdati.com)

Water as the most important element in the development of human civilization and the construction of urban life, the world, particularly in Iran has played a crucial role. Social life and the survival and prosperity of cities and villages, more than anything else on the water. "Water, is alphabet of developing" its water $\mathrm{Bi}$, "the desert, wordless denial" anhydrous "without water" (Dehkhoda Dictionary, 1960). Water in Islamic teachings and culture with concepts and spiritual values, especially so given that power and divine knowledge arises and everything will be introduced as the source and principle of life (Amin Zadeh, 2003, 68-71). In Islamic traditions and Quranic verses in Genesis Creation refer to the role of water. In the Holy Qur'an many times the word "Mae" used and has not been studied in many different ways: "And every living thing of water raised." (Surah prophets, verse 30). Due to the climatic conditions of the average rainfall in most parts of the world rainfall is less, it can be said that water was considered as one of the most important concerns of the Persians and the biggest challenge to the people of this land (Haeri, 2007, 11-17). The scarcity of this precious fluid, the Iranians hundredfold value of the material and put it in a position of prominence. As the water as a divine gift of waste that is highly valued and have avoided. The villages and towns came into existence and developed some dating back thousands of years. These are all indebted to the invention unmatched agility that water from deep soil drillers tried out and gave green light to the land. Depth markers and surrounded their predecessors hydraulic structures on water engineering knowledge (Javaheri, 2006, 20). History is always and everywhere the same water has been achieved. In the meantime, many in the Iranian desert existence and civilization throughout its long history and long-standing, structural owe seemingly simple, but very valuable and are completely indigenous. It is nothing but a subterranean structure. According to Bastani Parizi, dug canals is an epic, epic life and death Great to replace death with life. Aqueduct having such an old engineering system has been developed during the long centuries. All dimensions and technical fields such as architecture, geology, hydraulic, mechanical, structural, etc. are included. Roles and Functions given the critical dependence of this vital human material, not secret in history. 


\section{The Importance of Water in Ancient Persia}

In ancient Persia, the water source of immortality was the messenger of light and purity. Water and its role in spiritual and physical purification and recognition in mythology and look at it as a symbol of birth and fertile and symbol of purification, position of prominence in the human mind has long been allocated to (Kavandish, 2003, 144). In other words we can say, water in the world and ancient myths and in the context of the thoughts and beliefs and the beliefs of each period and its continuity and evolution in the overall context of the history and current culture, so its presence in the living culture of today, had significant results. In Iran and lands in the field of culture and language more perfect, in the Iranian world, the importance of belief in mythical ancient water and longtime detailed system and various technologies to exploit it, compared to other regions of the world with the index. Continuation of the characteristics of the historical developments, and they survive to our time, water as part of a dynamic and living cultural heritage has raised (Mir Shokraei, 2003, 3). Iranian attitude towards water for a long time, vision has been sacred. In ancient Persia, among the four elements of water has been, and Zoroastrians believe that after the fire, was considered the most sacred element (Bagheri, 2000, 47). Once upon a phenomenon that undermines the sanctity of human Seals have efficient role and presence in his/her life and what is the holy month that passes through and is protected (Mir Shokraei, 2003, 3). Due to the special holiness of water in the East, especially among Iranians and Muslims, has always been a key element in the layout and shape the spaces. Architecture in the water and in the lap of nature, without distorting it makes, its presence announced. Houses of worship, shrines and temples with water and finally respect to the presence of water to form. Iranian antiquity, Anahita that Zoroastrianism was the guardian of water, and the value they placed large edifice dedicated worshiping the goddess of water guard, had set Anahita (Haeri, 2007, 33). "Herodotus" god of the Persians Anahita said that it is holy for the current flowing waters and creates joy. It must be understood that only water but also in ancient mythological aspect is also important in many ancient cultures (Bagheri, 2000, 47). This trend did not continue in ancient times and the water was transported by aqueducts, identity around its transmission by means of its subterranean community was formed. The identity arising from the existence of Iran in historical continuity, durability in civilization is made canal in the heart of the great Iranian civilization. There is no doubt in human history, water resources in all circumstances, the founder of ancient civilizations and ancient civilizations all around the large rivers such as the Tigris, Euphrates, Nile, etc. have come into existence (Lahmian, 2003, 93). Iranian 
civilization, of knowledge and learning has survived the generations that lived before us. World, ethnic groups and the influential teachings and knowledge in various fields of action for the development of a genuine civilization known, empire land at par with China, India and Rome. The inhabitants of the religion, literature and architecture are rich (Haeri, 2007, 28).

\section{Museum}

The means to balance the scientific criteria, structural performance and invent new forms. Which makes the human manifestation of the aspirations and desires. Therefore, developments in the architecture of life and human understanding. Architecture is the art of making not deconstruction, art representation no relation. Architecture is art of substantiality up. Architecture rate and rhythm and form an invisible life forms. In fact, a process which gives the project structure and the structure of the plan. Architecture appropriate to the nature and climate of the value of human space created in the wake of advances in technology and compatible with the environment. What should the technology in recent years has been the use of new materials, learn how to use less materials and energy, maximum efficiency is achieved. Design and construction of buildings in the future should new combination is a perfect match with the environment and materials. It should be noted that the museum and its construction by displaying objects and not the objects by displaying the museum building. Museum architectural features should be based on harmonious relations of space, light and works. Museum architecture should be adaptable to the booth and categorize objects and it will be considered. In the field of view, absolutely no space cannot be blamed. The smallest level should serve to provide museum and exhibition for the audience.

\section{Water Museum Glacier Garden Tehran}

For example, the case within the country, Water Tehran Museum is selected.

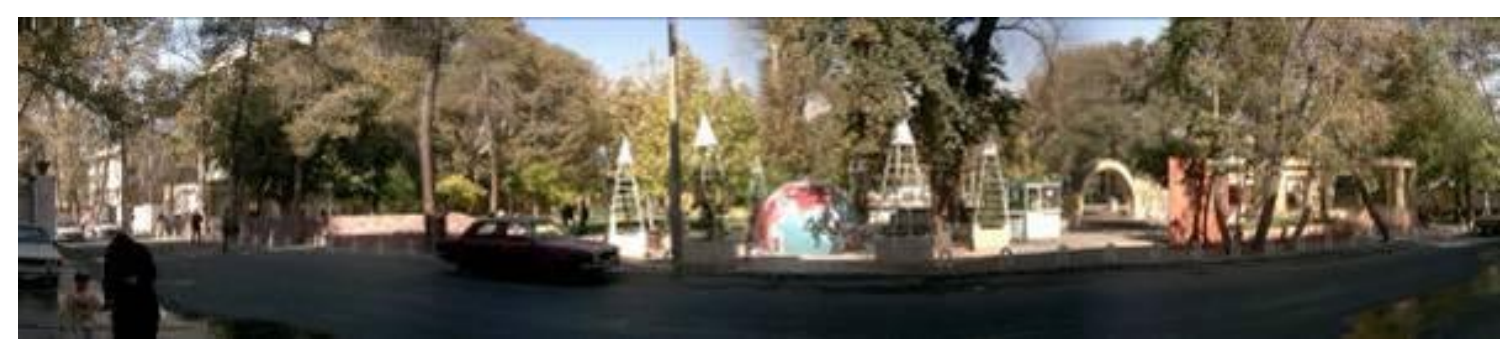

Figure 2. Panoramic view of the garden museum, Source :( saeedsun.ir) 


\section{Description}

Wrapping a piece of old garden in the midst buildings part of Tehran, incentive for municipalities to organize and plan it as a museum with water, the old garden maintained as a dynamic part of the city at the service of its citizens and visitors. A garden that has led to this area of insecurity. The high price of land in this area and the lack of open land around it, especially the lands with such an index position, the importance of this piece adds. The high environmental potential (trees, white, garden around) and social (being in different training centers) in the surrounding area even more important was the decision to use this piece. An area of 8256 square meter garden Water Museum in the northern region in the garden on the streets of Tehran and Tehran's refrigerators have been constructed in Region 3 after reform, the garden area was mentioned to 7161.9 square meters. The garden has a general slope of 2.85 per cent from north to south that initially has 382 trees and shrubs of sycamore, pine Tehran, mulberry, walnut, ash etc. Article 190, of which it is used and the rest of the dry and illness, have been removed. A stream, derived from an aqueduct from the northwest angle into the garden and after a third of the length of the pitch to turn to the East, the garden is over. The project was put into operation in the summer of 2001 after 5 years. In general, the design and placement of the various elements together, were the likely causes their most valuable old trees, aqueducts main street leading to the garden and access to the garden (street refrigerator) is. Without these factors, the piece of land was transformed into one of the city plaques, without any sense of the value of the environment and specific location that any sense of belonging to area residents was not looking. Thus, life and critical value of the land in that place to visit, entertainment, excursions and public life and survival depends on trees and aqueducts and other factors its location.
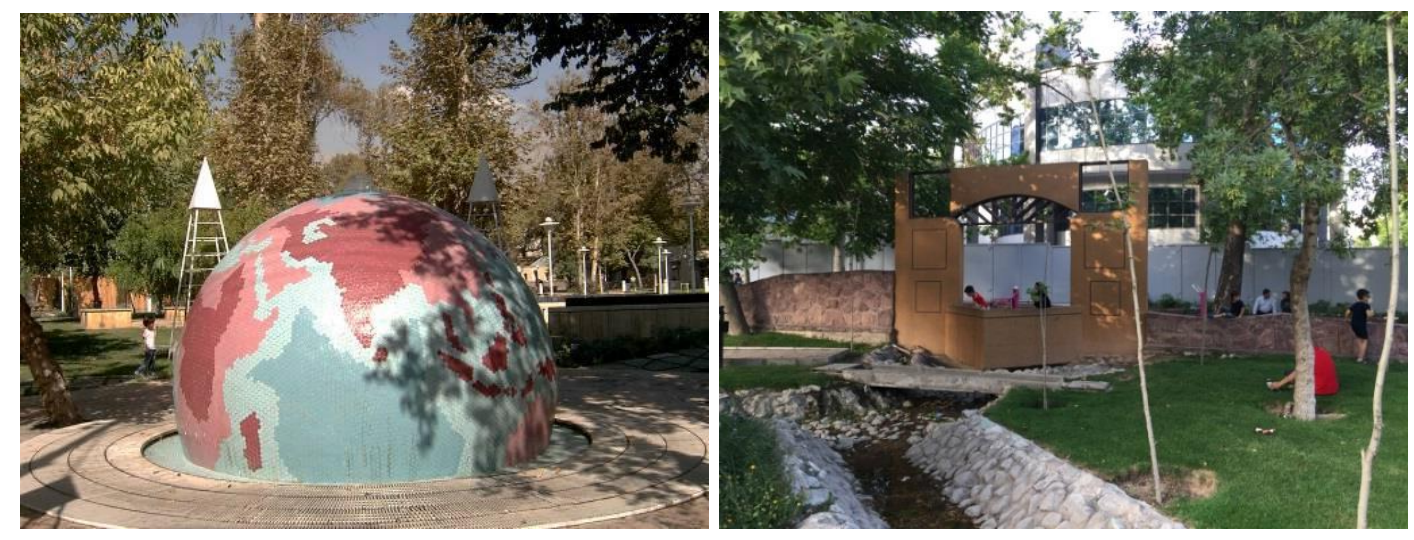

Figure 3. Internal view from different angles museum, Source :( saeedsun.ir) 
According to the designer collection of exact first step was to identify the species found in garden and the trees are sick and need to modify the value stored by the trees and on the map were drawn. The presence of this precious tree with running water in the garden, potential to achieve optimal environment and the urban fabric interwoven with lively notes. This line of thought leads to designer, to form the skeleton of the original design based on the iconic elements and a charge of special memories. In order that the core of the design, the direction of water flow constantly adapted in the garden and main entrance gate in the old garden gate is formed. The spatial arrangement of synthetic elements incorporated in the garden of the museum building, pavilions, services, etc. in such a way that least affected may notice the trees. Park in the eastern part of the family gym is under construction. The combination of these two sets of family club museum and aquarium water can be inviting more people.

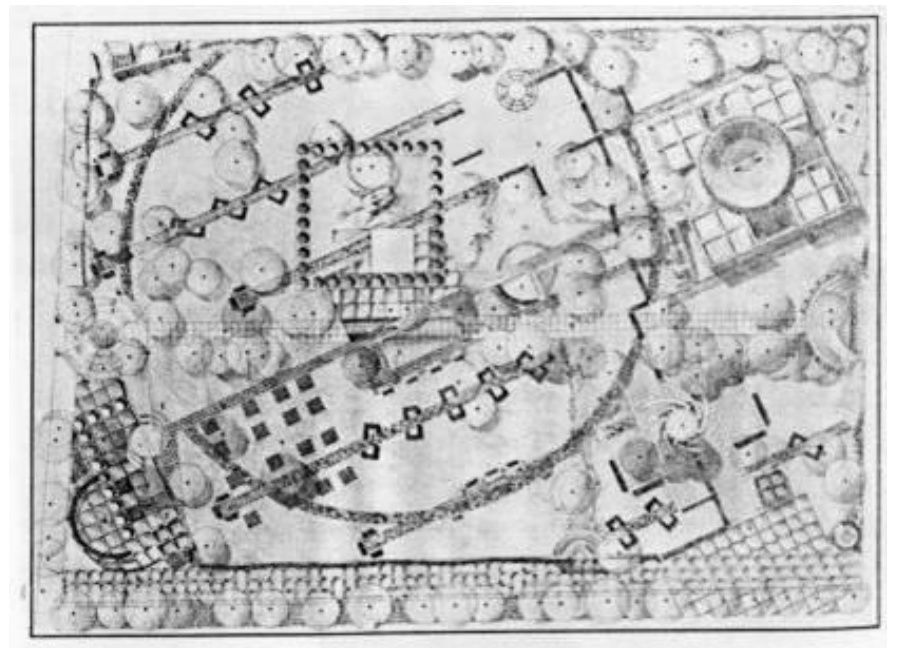

Figure 4. Plan of the museum, Source :( saeedsun.ir)

\section{Analysis}

1. Water Museum Garden relationship with the main stream

'Another point that can be pointed to it as well as possible and the relationship of those is important and the edge of the road refrigerator (side garden entrance) and pass their first encounter with this series.", 


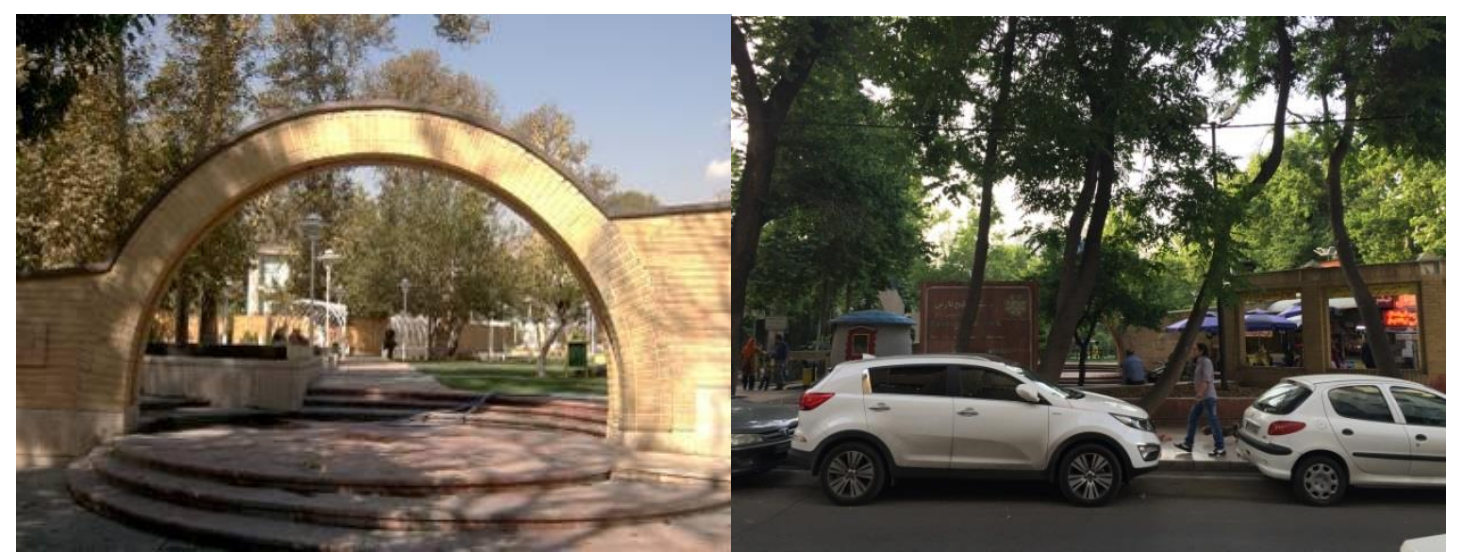

Figure 5. Internal view of the Garden Museum, Source: (author)

If the person who has passed at least once through the streets refrigerator be asked what is taken from the series. Only his mental picture rows of trees, brick and Korean large semicircular shell, which symbolizes the earth, as the gateway remembers collection. In fact, the demand has been the designer. Because he believes that we should put the synthetic elements such as building a barrier in front of the entrance to see people brought into the garden space. But it should be noted that in the narrow streets and high-traffic times, such as the refrigerator, even a few finite element but the caller had also becomes invisible, whether to equip the front entrance and strongly and more attractive with the flow of people and street did not need to more carefully? The main entrance to the south side of the center is set. View the role of water in the life of the planet on arrival attractive idea. Most children in the beginning, by touching it, the water closely and feel your hands are wet. But the blue planet that is visible only up close. Eight cedar enclosed in metal pyramid that have surrounded the planet. This vision of postmodern thinking that has caused the elements were marginalized in the text. The emphasis is on the cypress, the tree's natural role in the conflict. Iranian cypress tree in the garden is stronger and more important. And the question of whether the viewer with elements such as concrete and metal decorative trees need to have? Rigidity of these materials is contrary to the viability of the tree and its growth will be prevented in the future. Along the axis of the main entrance and along the east side of central park within $8 \mathrm{~km}$ north of the garden from the street to access the refrigerator is intended, of course, with flooring and flowing water bodies and permanent crossing of the border, a sense of direction finding antenna body in spite of the garden to ignore the real scope of the Municipality plans to use the data. The streets suddenly cut off access but rather part of the garden is the garden (Ranjbar, 1996, 13-21). 

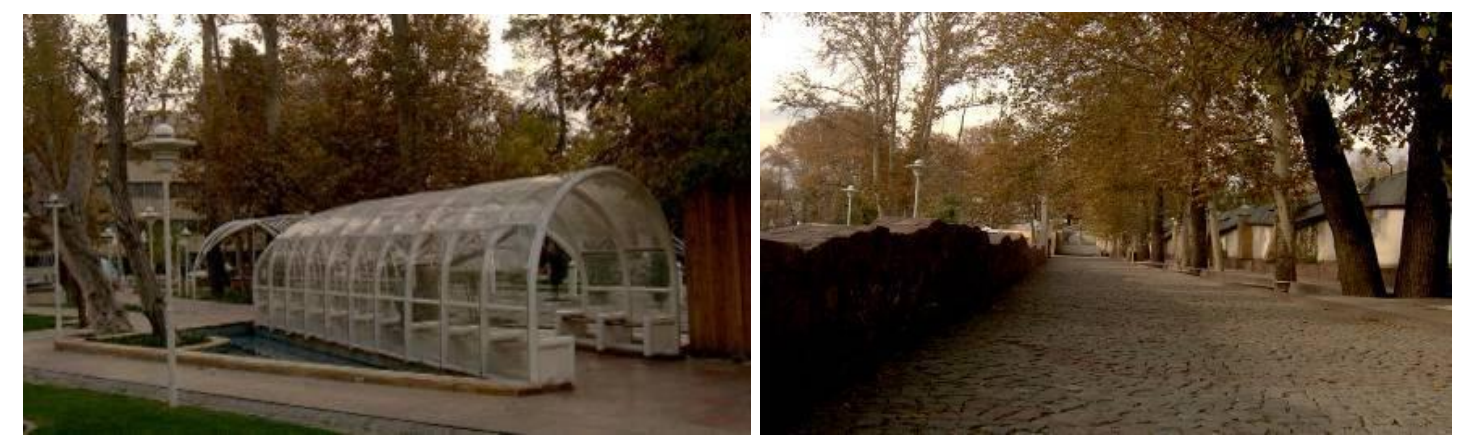

Figure 6. Internal view of the museum from different angles, Source:( saeedsun.ir)

In-wall approach, combining materials such as stone and brick is reminiscent of traditional materials. Created a body that covers the living platform, and a garden. Designer style influenced by postmodernism roof to help the body has been trying to remember the old walls of Shamiran.

\section{Fountain}

Input shaft fall on the end wall of the garden leads to a fountain, water falling from a height and shows a curtain of water formed and one can pass from behind the water curtain where to sit or be embedded and open spaces through the water curtain and move people to witness. This axis is the axis perpendicular to the body gardens and other axes are rotated due to an unknown reason. The confluence of the longest diagonal axis that connects the cafeteria and the main axis of the building aquaria, through the tunnel has been covered Plexiglas modern style. Water loss on the tunnel, passing under it felt dive into the cascades of glass there, the sound of water falling on Plexiglas, fabulous experience will follow. What falls under the Plexiglas tunnel, causing a pause in person benches are placed under the tunnel may sit with him is possible. Green design aimed at the beginning of the tunnel for fences and adhesive is covered with plants. Designer style influenced by post-modernism tries to iconic elements of classical gardens Iranian borrowing. Although the color blue tiles inside the three large rectangular pool is located at the beginning of the main shaft, from Iran's dock tile colors drawn triangular form they are strongly opposed to it. Fountain square for square-shaped fountains that are moving experience to create the water and getting wet from the field Bartoli and Citroën Park in Paris. The fountains are circular center that has been implemented and 
flooring along with its neighboring fountain which is a combination of stone fountain in the square spaces that have been created by cypress trees.
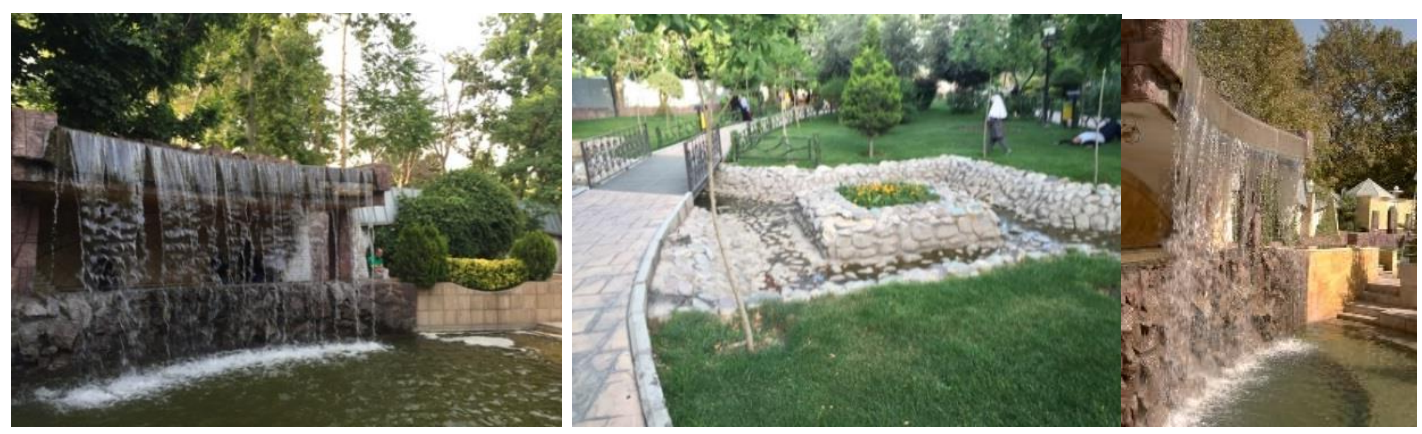

Figure 7. Internal view from different angles Museum and Fountain Gardens, Source:

(author)

Broadcast, ground water on the rubble of another water effects in the garden. A pleasant voice, and air conditioning caused by the ground water. In ancient reservoir of water effects seen using it. Water voices can be heard in all the gardens and waterfront binding factors as varied sound. The subterranean water available on site after a third ground for rejecting the transverse garden, then working its way to the south. In a way that is in the earth. The designer uses creek and an artificial pond that is inspired by Japanese gardens, water has emerged.

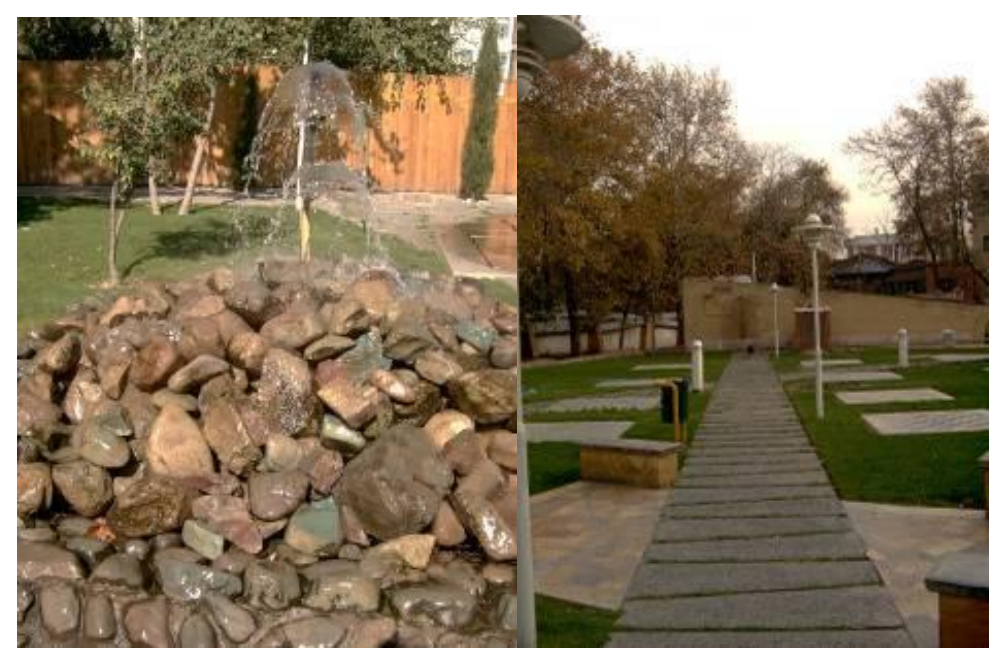

Figure 8. Internal view of the museum from different angles, Source :( saeedsun.ir) 


\section{Research Methodology}

In this research, qualitative research methods and applied research of the ways in which cross - is used. Study on the influential elements in the characterization of the project as well as review case studies have been done. This means that scientists studying the characteristics of effective elements and uses comments relevant experts, to achieve overall results. Then extract the positive and negative results with regard to the use of performance-oriented approach of bionic architecture to create spaces in the museum in pure water, summed up the positive results and the details associated with the approach to deals. In the present study, the elements influencing the research questions to be fully explored and elaborated. Then the required data collected and generated and coded line by line. In fact, at this stage is that the open coding, data collection elements to be labeled and classified to produce concepts that are the basis of objective research. In the next step, which is encoded driven, categories and subcategories are systematically linked improved. Here the researchers chose an open coding categories and it is the main purpose of research, as a central phenomenon, then it connects to other categories. In simple terms, each of the codes extracted from the previous step, in the table entitled table axis linear encoded with a two-way relationship with the codes themselves, with the goal of reaching approach to research, communicate them. The table features a column and its relationship to architecture is expressed in the next column. The results of this phase, called the research model and draw a chart that listed under the title picture. This model depicts the relationships between the data. The final phase is selective coding. In fact, the process of reconciliation and purification theory. Now determine the theoretical model, the researcher laundry services, filtration and removal of additional items that had been brought in axial coding table deals. Finally, after refining, the number of data that bilateral relations have had their data against elected that each one-way working to achieve the main goal of the museum's architectural techniques permit, allow the designer to help them achieve their goals.

\section{Analyze Research Data}

In the present study, according to the survey, the relationship between environmental variables, including the architectural work permit, water and nature, and also some of Vitruvius principles, based on bionic architectural pattern and practice of architecture and design principles can be deduced. Described steps, define and explore the relationship between variables. After sampling and data collection study in the theoretical framework, the 
analysis of the factors, variables in this study were obtained. Based on the relationship between these variables, hypothetical model was proposed and the analysis, review and modify the route. After confirming the accuracy of the proposed model, based on the same design principles were derived. The findings of the study, was formed for water museum design principles are explained below. In the first step leading to the first open coding categories to achieve. In the second stage of selective coding and final phase encoded axis.

\section{First Stage}

Entirely about the architectural work permit, water and nature, as well as some principles and definitions and theories theorist Vitruvius explained the name, the date mentioned architecture. However, data gathered here can be coded and categorized. In fact, the researcher in the department is responsible for tagging the data. According to the proposed definitions of some of the features discussed, including about performance-oriented, three of Vitruvius, architecture and solutions permit this style. Featuring some of the architectural features necessary as the body of museum architecture is known, to design such move, which includes pause fluidity and dynamic design, expanded functionality and flexibility, readability, the relation of part to whole and vice versa, space green museum, respect for the hierarchy to be included. Also on the main elements affecting the project, and is now trying to explain the implications of the elements that can contribute to the Water Museum, extracted and classified. The images below show data extraction and classification can be seen.

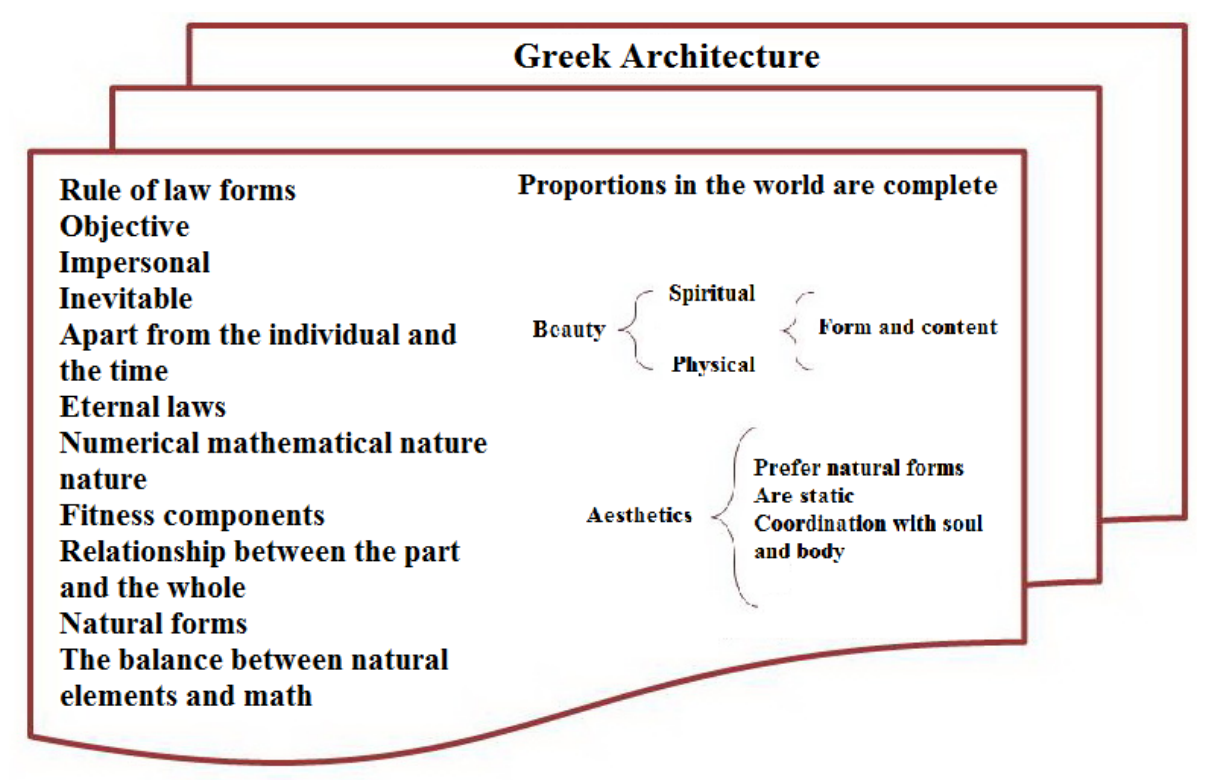

Figure 9: Key words according to theoretical studies about the architecture of Greece.

Source: (author) 


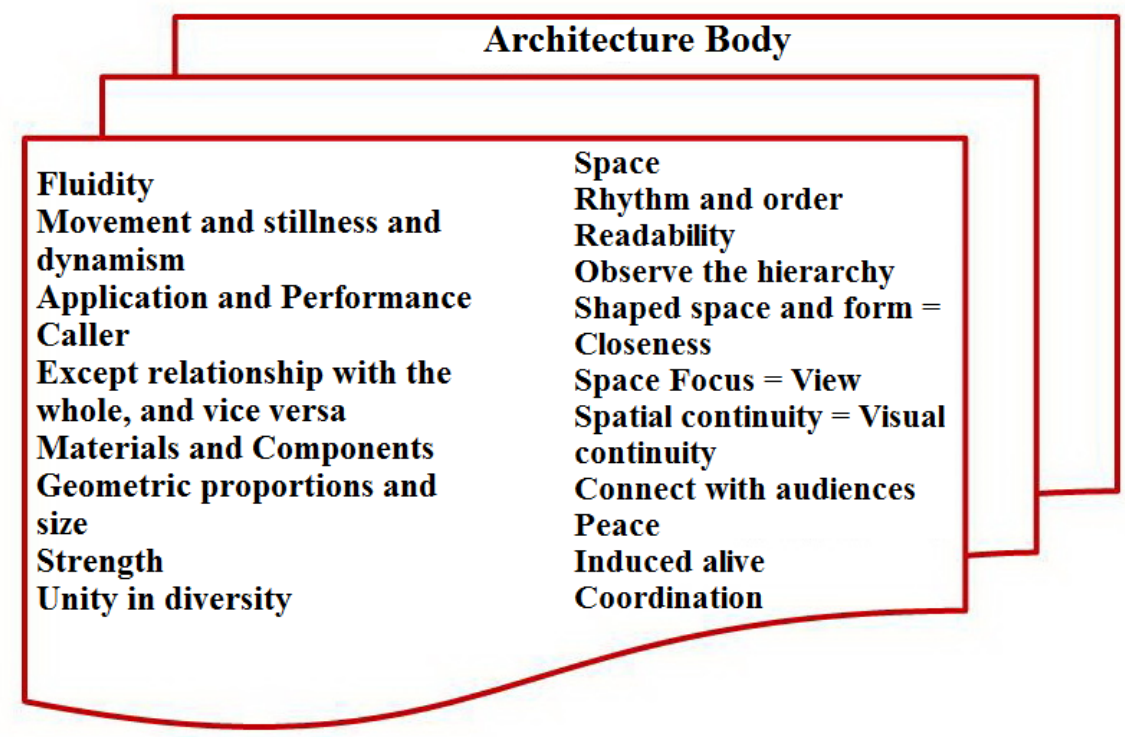

Figure 10: Key words according to theoretical studies in relation to the body architecture.

Source: (author)

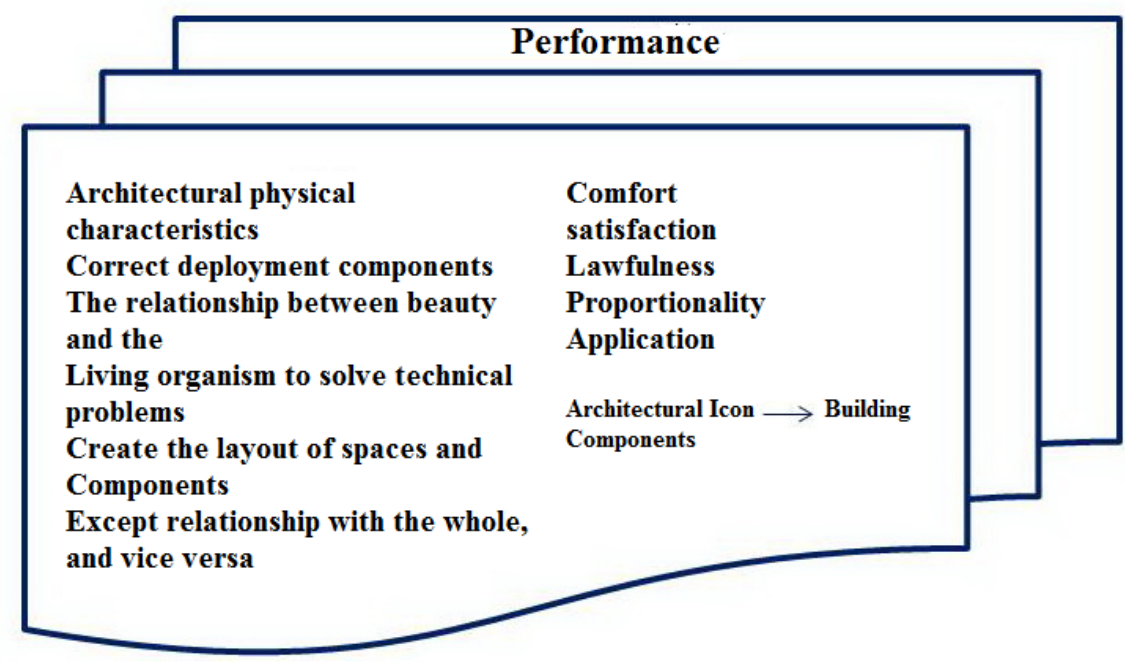

Figure 11: Key words according to theoretical studies about the performance. Source: (author) 


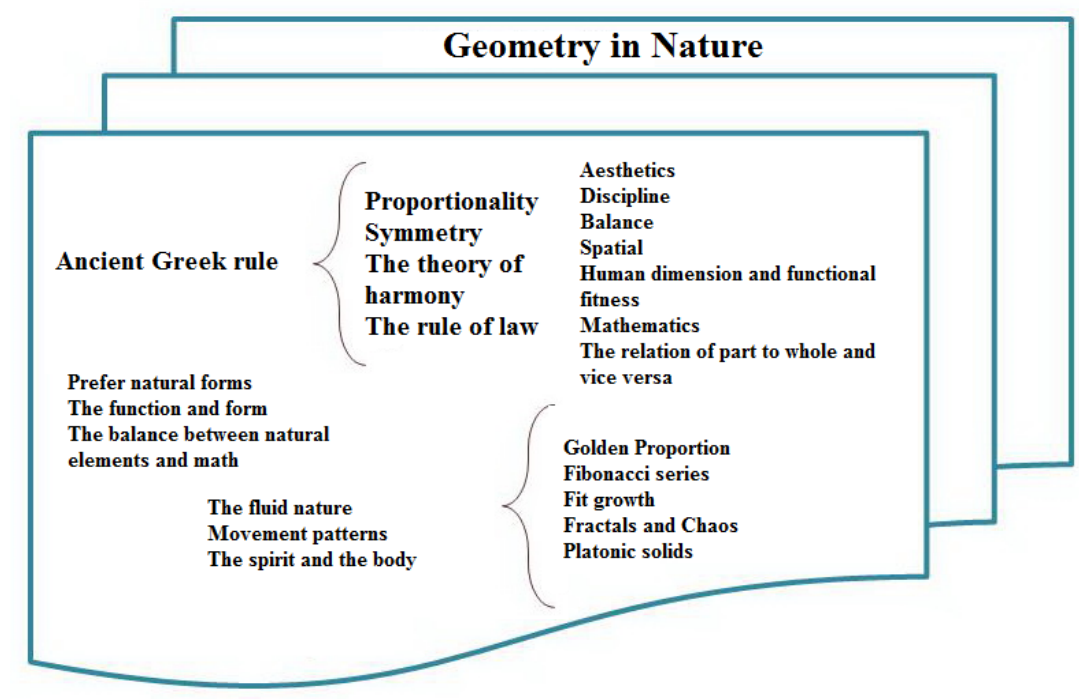

Figure 12: Key words according to theoretical studies in relation to the geometry. Source: (author)

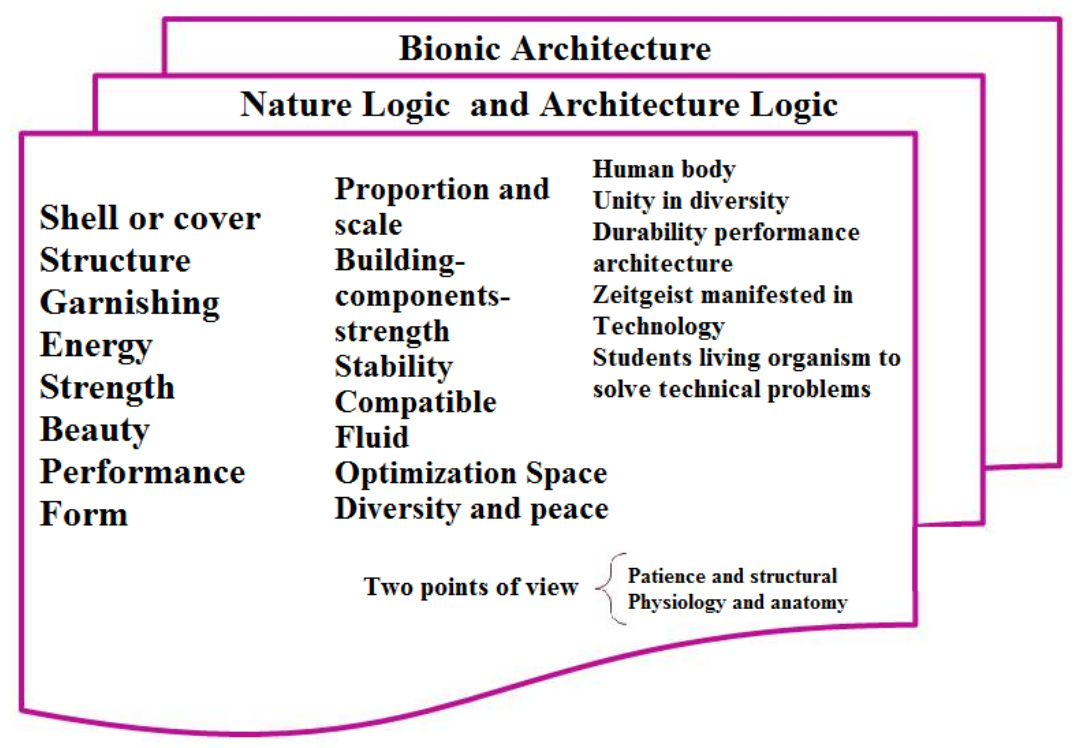

Figure 13: Key words according to theoretical studies in relation to bionic architecture.

Source: (author)

There seems natural principles of Vitruvius in the contract and the natural principles, enshrined in ancient Greek logic is the same categories that would have attracted the attention of all philosophers. These issues are so universal that not only architecture but also aesthetics and ethics can explain. In fact, the three principles of operation, construction, and architectural shape for a full explanation of no integrity and no parity. 


\begin{tabular}{|c|c|c|c|}
\hline Concepts & $\begin{array}{c}\text { Articles } \\
\text { (components) }\end{array}$ & Meanings & $\begin{array}{c}\text { Articles } \\
\text { (components) }\end{array}$ \\
\hline $\begin{array}{l}\text { Intuitive } \\
\text { motion }\end{array}$ & Fluidity & & \\
\hline $\begin{array}{c}\text { Vertical } \\
\text { movement }\end{array}$ & Performance & $\begin{array}{l}\text { Apart from } \\
\text { the time } \\
\text { Apart from } \\
\text { location } \\
\text { Formal } \\
\text { beauty } \\
\text { Functional } \\
\text { beauty } \\
\text { Natural form } \\
\text { Free space } \\
\text { Modeled } \\
\text { from nature } \\
\text { Shape }\end{array}$ & Beauty \\
\hline \multirow[t]{2}{*}{$\begin{array}{c}\text { Move on the } \\
\text { horizon }\end{array}$} & Proportions & $\begin{array}{l}\text { Stability and } \\
\text { proportions } \\
\text { Comfort } \\
\text { satisfaction } \\
\text { Estimated } \\
\text { body } \\
\text { The balance } \\
\text { of form and } \\
\text { structure }\end{array}$ & Stability \\
\hline & & $\begin{array}{l}\text { Proportions } \\
\text { of } \\
\text { components }\end{array}$ & \\
\hline
\end{tabular}




\begin{tabular}{|c|c|c|c|}
\hline $\begin{array}{c}\text { Physical } \\
\text { movement }\end{array}$ & & $\begin{array}{c}\text { Overall } \\
\text { compatibility }\end{array}$ & \\
& Relation of & \\
& Dynamism and & Relation of \\
& diversity & Bart to whole & part to whole \\
& & & \\
\hline
\end{tabular}

Table 1. Concepts and components of research. Source: (author)

\section{Second Stage}

At this stage, data classification in step before we compared line by line and attempts to explain the relationship between linear and interactive data is established. This relationship must be based elements to finally come to a conclusion opens up new architectural framework. In fact, water properties such as fluidity and movement to come to the aid architecture with its strong presence in space, the aim of the study and researcher into the body and soul of their architecture. Establish the relationship between the data path in order to reach this aim appropriate for the designer makes clear. In Table 3, data extraction and classification in step had been before, are linked together linearly. But before presenting the table, to better understand the relationship between elements, the image is presented to help chart the position of each element of the plan is clear. In this image through graphical charts, the area of influence of the elements, is shown. As can be seen, the first layer contains water as a basic element and the museum features included in this research field and in the end the truth must permit a direct relationship with their characteristics. The second layer of fabric architecture that is intermediate between the first and third layers and a result that is obtained from a previous relationship between the two layers. The space under the rules of Vitruvius attributes, bionic architecture and performance in a way that comes to architecture, structural design. As a result, the aim of which is to provide water permit Museum achieved. The researchers' main task is to make a connection between the first and third layer and achieving major result is the second part. 


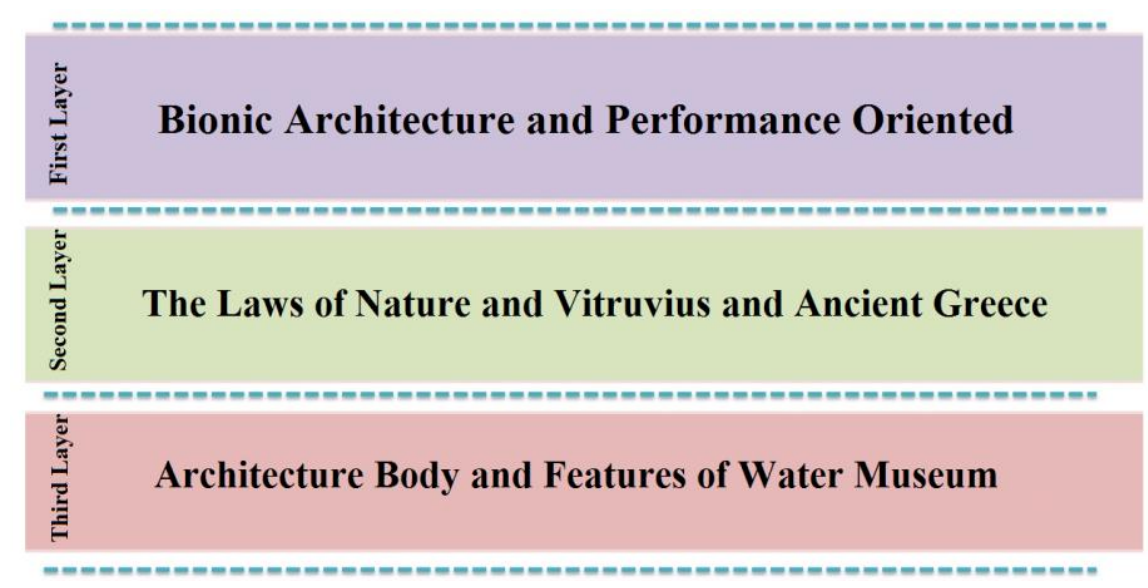

Figure 14. Graphical chart, the domain of effectiveness of existing elements

Now clear the area of influence of the elements in the research can be a linear relationship between the two strains of classified data indicated in the table. This theory of creation through systematic coding and analysis methods enable direct. It involves three types can be compared; first phenomena to discover the similarities and how to modify them in a variety of conditions are compared with each other. It operates on the basis of similarities found in the general categories and their characteristics can be identified, which will be the basis of future concepts and assumptions. Next to categories made phenomena of saturation characteristics compared to the theoretical concepts. The purpose of this detail enhancement concepts, conceiving them while increasing categories of extracted features or explore the possibilities of new concepts. 


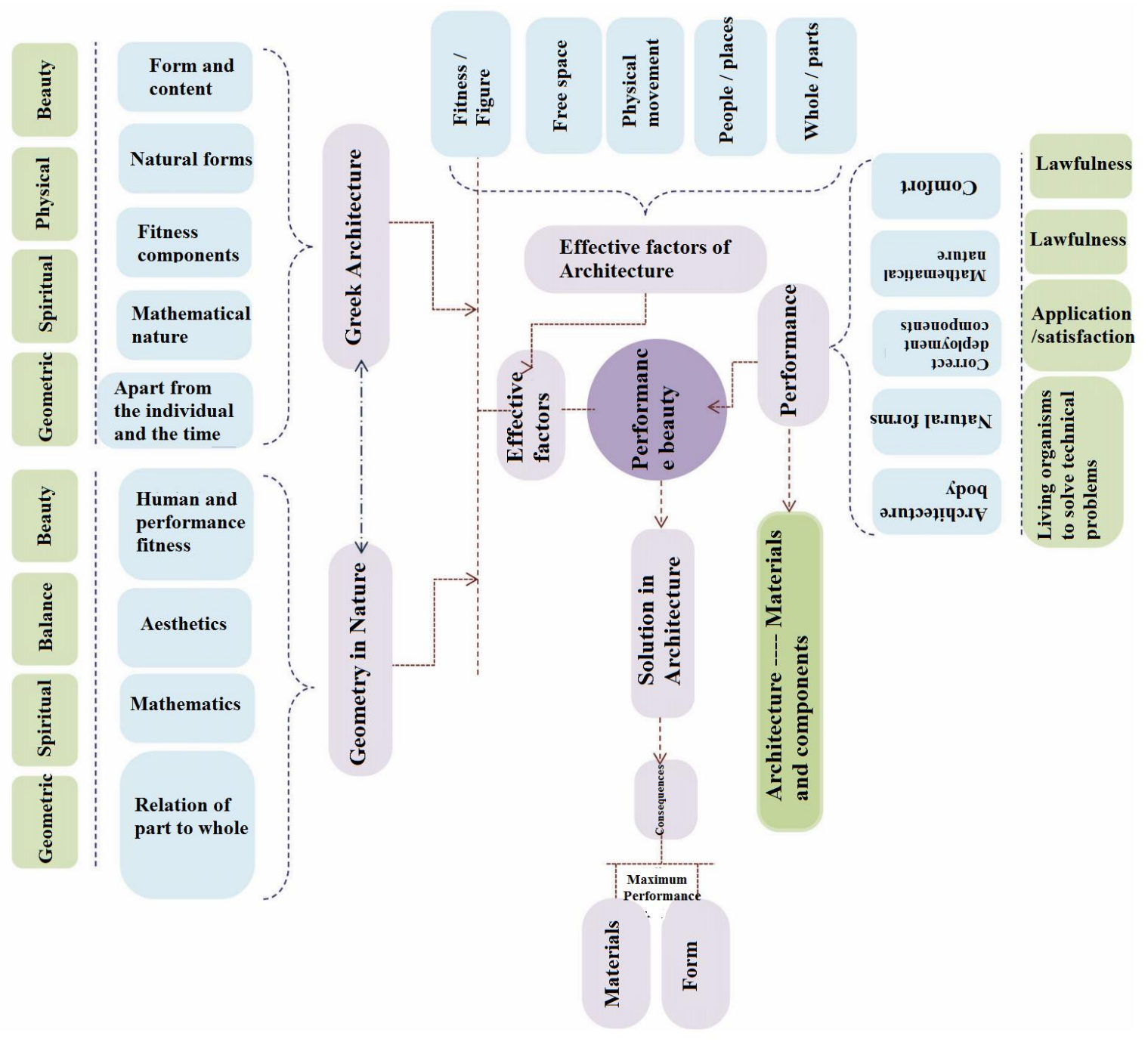

Figure 15. Chart 1 axial coding pattern. Source: (author) 


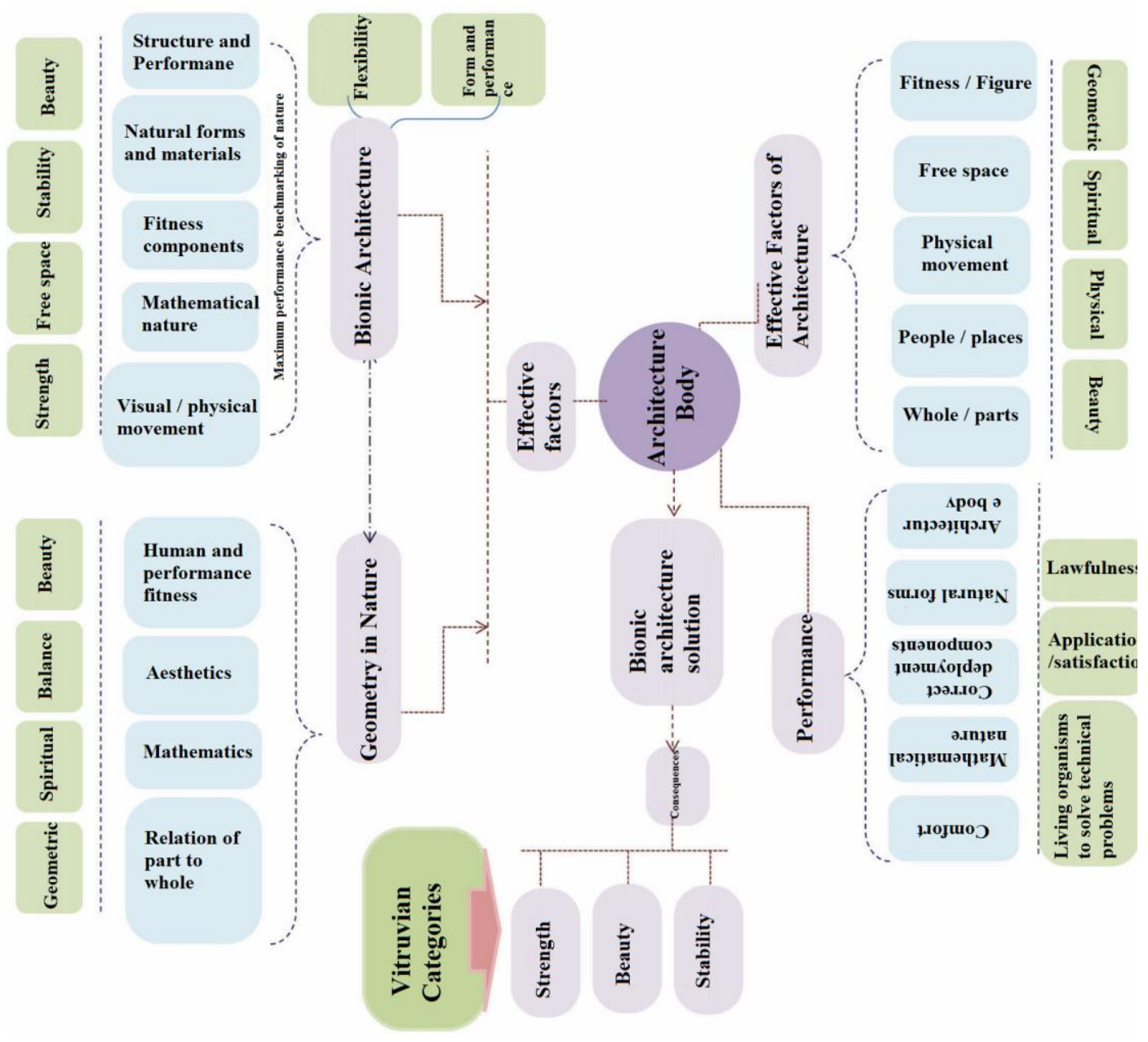

Figure 16. Chart 2 pattern axial coding. Source: (author)

Now, given the patterns across the open coding, axial and selective research questions can be answered:

What approaches to understand the laws of nature to achieve beautiful performance means maximum performance in materials and form; in the design?

Figure 17 coded chart pattern 1 in response to the first question.

* What solutions using bionic architecture to define the strength, beauty and performance can be reached Vitruvius?

Figure 18 coded chart pattern 2 in response to the above question. 
By bionic architecture providing performance-oriented ideas on what can be achieved lasting influence?

Figure 18 coded chart pattern 2 in response to the question.

\section{Conclusion}

This stage, the stage of refining the data. Using the data in Table 3 strive to select relationships that will help researchers in order to achieve the objectives. This step is optional coded and important data affecting the design of axial coding were selected. According to the project tries to pick out useful relations and the instructions provided in the form of work.

1- Fluidity: To create a sense of fluidity in architectural form can be enjoying the fluidity of the plan, was to free movement and style in general. Like the flowing river, the main requirements to achieve this goal. This move can be shown in two parts to the plan. The use of windows drawn in form and sense of movement and fluidity will have a great effect on the facade. Combined with horizontal movement of the vertical movement of the audience. And major and minor aspects of their route according to their type of use that can be determined.

2- Dynamism and diversity: Change in the size of the windows along the inside of the outer shell and spatial dynamic form, it is important. The use of unfamiliar forms of natural, marine plankton form in the project that has recently received attention jewelry designers, is recommended. Use a variety of different push and pull material together intelligently, such as concrete, ETFE, plastics, fibers variety of translucent concrete, changes in height and proportions, creating depressions and indentations, broken and continuous spaces, curved and fluid, using the various ceilings, changes in the degree of closeness of space and closeness of mesh like material, new material made of plastic fibers and concrete, open and semi-open space including space create a dynamic and diverse solutions and different perspectives.

3- Flexibility: Movable partitions flexibility in the project and the ability to change the interior space creates a sense of change from moment to moment, it helps the dynamics of space. Free proportions everywhere in the halls and rooms of the museum, can meet different needs at different times, and in the spirit of the times to be 
blown in place. Multi-purpose use of the space in vertical and horizontal surfaces, using natural and organic form suitable for any space, will create flexibility in the project.

4- Form and performance: Architectural space designed with bionic approach in some areas of performance can be better than to have available spaces. Also, a space can be created that instead of overcoming environmental degradation, coordinated and to protect nature and be available at the same time, provide more comfort for the userspace. By trying to understand the laws of nature by seeing, feeling, hearing, or smell, excellent design that is aimed to achieve structural performance, functional requirements and aesthetic are combined with each other.

5- Proportion and scale: In designing a museum for display, certain points must be considered to visitors of the museum can easily and without the spaces are winding it damned clear path to move easily come and from all theaters if you wish to be removed from the building. Diversity in the direction of motion, a variety of interior elements, whether in furniture or in the material, the use of innovative geometry in plan and facade, modular system for tablets and form wine and glass to create perfect visual perspective to clients' concerns, including the design of the project.

6- Proportions of the component, and vice versa: Ideas from the various forces of nature to architecture that helps to organize and mix in the form of units. Components without the balance and composition of a whole may seem, but did not appear to be unrelated.

7- Hierarchy: Space to fit the appropriate hierarchy and short breaks, raise efficiency and enthusiasm museum visitors to stay and see increases. Taking advantage of furniture designed and properly can be effective to relieve fatigue in theater, museum design, will be conflicting juxtaposition properly. The initial binding of each museum object relationship and the audience. Designer, in the organizing of the museum should try.

8- Beauty: In general, an important factor that exists in nature and man has used them to build their buildings, are as follows: crust or cover, structure, decoration, energy to achieve the beauty of natural forms of water use, according to the material presented in three different modes of solid, liquid and gas as well as coastal plankton and plankton in the water used. One of the most important points is that bionic architecture 
of the building itself induce palpitations blower. To achieve this natural beauty, the use of new materials and self-cleaning of the facade and interior plan is proposed.

9- Stability: The need for services to be felt in every space. If human basic needs and the development of other vital needs does not carry with them everywhere. It needs quite tangible and material nature, and with the same features and more intangible human needs more sublime and distinguished objective. Need to comfort others and of meeting the needs of the human body can be built in any space that should be considered. For the museum for visitors to have a special charm meets the needs of his body and put him in a familiar and comfortable environment, should be designed as a combination of public and private spaces, to visits, while forgetting the confusion, in a state of equilibrium and in contact with people and objects more. This space functions provides short breaks and entertainment venues and recreation.

10-Open spaces: Basically, in open spaces plan, it should be noted the possibility of using them at all times of day and seasons. In plan of entertainment - tourism centers, open spaces always sit in the center between different areas. Vegetation in open spaces design should be considered as a design tool. Diversity in shape, size and composition of plants can pose them as architectural elements. 


\section{Referances}

Amin Zadeh, Behnaz, (2003). Water, Architecture and Urbanism of Tehran Muslims. Specialized Magazine of Book of the Month Art.

Cavendish, Richard, (2003) The Primordial Chaos of Water Symbolism.Ttranslated By Saeed Rezaei. Specialized Magazine of Book of the Month Art, Tehran.

Dehkhoda, Ali Akbar, (1960). Dehkhoda Dictionary. Publication of Tehran University. Tehran.

Golabchi, Mahmoud, (2014). Bionic Architecture. Tehran University. Tehran.

Haeri, Mohammad Reza, (2007). Qanat in Iran. Cultural Research Bureau. Tehran.

Hagan, S. (2001). Taking Shape: A New Contract Between Architecture and Nature. Architectural Press, St.Louis,USA

Javaheri, Parham and Javaheri, Mohsen, 2006, "Challenge for water in Fars ancient", Samar Publication. Tehran.

Lahmian, Reza, (2003). Water, the Origin and Transmission of Civilizations. Tehran: Specialized Monthly of Book of the Month Art.

Margolius, Ivan, (2009). Architects + Engineers = Structure. Translated By Mahmoud Golabchi. Publication of Tehran University. Tehran.

Mir Shokraei, Mohammad, (2003). Culture and Water. Specialized Magazine of Book of the Month Art. Tehran.

Raisnia, Rahim, (2004). Azerbaijan in the course of history of Iran. Tabriz: Nima Publication.

Ranjbar, Nahid, (1996). Article of Water Garden Museum. Municipal Partners' Internal Magazine Publication. Issue 52.

Vitruvius, Polio, (2009). Ten Books of Architecture. Translated By Rima Fayyaz. Publication of Art University. 